\title{
EDITORIAL
}

\section{Addressing the epidemic of scientific misconduct}

\section{Enoka Corea and Himani Molligoda, Co-Editors}

In the recent past, a host of papers and editorials have bemoaned the rising number of scientific articles that are retracted, mostly due to scientific misconduct ${ }^{1,2,3}$. These retractions have taken place all over the world and in the most prestigious journals. This phenomenon has been interpreted as a symptom of malaise in the scientific enterprise and has generated calls for urgent scientific reform.

The main forms of scientific misconduct resulting in retractions are fraud (falsification or fabrication of data), duplication and plagiarism ${ }^{1}$. Falsification of data includes altering or omitting data to generate 'cleaner' results while fabrication includes making up data or results. Duplication or redundant publication is publishing the same data in more than one journal and plagiarism is the process where the researcher, deliberately or accidentally, passes off another's ideas, data or writings as their own. A meta-analysis of surveys on the subject found that $2 \%$ of scientists agreed that they had committed research fraud at least once and $14 \%$ had witnessed it in colleagues ${ }^{2}$.

\section{What are the pressures that induce scientists to commit fraud?}

The so-called 'publish or perish' culture has moved out from academia and into the general biomedical community. Incentives, such as the research allowance of the Ministry or Health, while promoting research culture has, inevitably, resulted in attempts to subvert the process. Inadequate funding has brought about a hypercompetitive research culture with more and more scientists competing for less and less resources. Since research grants, jobs and promotions are awarded on the basis of previous successful research, measured by publications and citations, scientists are pressured to publish faulty research, divide up the research findings of a study into parts and publish each part separately (salami publication), submit the same paper to two journals (duplicate publication) or submit the same results in two papers (redundant publication).

The prestige that comes with publishing in a high impact journal may tempt scientists to 'doctor' the data to increase the chances of acceptance. This may account for high impact journals having the highest rates of retraction ${ }^{3}$. It is interesting to note that males comprise a larger proportion of researchers detected to have committed misconduct which may indicate that competitiveness is responsible for driving this behavior ${ }^{4}$.

\section{How can this problem be addressed?}

One strategy is to build awareness among researchers regarding research integrity and publication ethics. Such training should be built into undergraduate, postgraduate and doctoral courses, along with the regular training in study design and statistical analysis. Since studies have shown that research misconduct occurs at all levels, such training should be reinforced throughout the scientist's career ${ }^{4}$.

An increase in funding of research will reduce competition for scarce resources, one of the main motives for research misconduct ${ }^{5}$. Increasing the number of women in science may also reduce research misconduct. Reforms in research grant review such as promoting collaborative research and evaluating the quality of previous 
research, rather than quantity, may help ${ }^{5}$. Other cultural reforms such as reducing pressure on research trainees to produce publishable results and reducing the effect of impact factors and citation index on academic tenure and promotion while simultaneously emphasizing scientific quality and collaboration will have long term beneficial effects ${ }^{6}$. Scientists need to be taught to appreciate the contribution of their peers to the advancement of science i.e. its derivative and collaborative nature ${ }^{6}$.

Punishing research misconduct may also act as a deterrent. In the most prominent cases, loss of reputation and charges of fraud have ensued. At the very least, journal editors should clearly state the reason for retraction of articles. National monitoring agencies such as the US office of RI may play are useful role in investigating, documenting and punishing research fraud ${ }^{4}$. Faculty and trainees should be educated to report misconduct to the relevant agencies ${ }^{7}$.

It is likely that a systematic overhaul of the scientific establishment is on the cards. One objective of these reforms is the reduction of error and misconduct in scientific research which should result in great benefits to both scientists and humanity at large.

\section{References}

1. Castillo M (2014). The Fraud and Retraction Epidemic AJNR Am J Neuroradiol 35: 1653-1654 https://doi.org/10.3174/ajnr.A3835 PMid:24356674

2. Fanelli D (2009). How Many Scientists Fabricate and Falsify Research? A Systematic Review and Meta-Analysis of Survey Data. PLoS ONE, 4(5), e5738. https://doi.org/10.1371/journal.pone.0005738 PMid:19478950 PMCid:PMC2685008

3. Fang F C, Steen R G \& Casadevall A (2012). Misconduct accounts for the majority of retracted scientific publications. Proceedings of the National Academy of Sciences of the United States of America, 109(42), 17028-17033. https://doi.org/10.1073/pnas.1212247109 PMid:23027971 PMCid:PMC3479492

4. Fang F C, Bennett JW \& Casadevall A. (2013). Males Are Overrepresented among Life Science Researchers Committing Scientific Misconduct. mBio, 4(1), e00640-12. https://doi.org/10.1128/mBio.00640-12 PMid:23341553 PMCid:PMC3551552

5. Fang F C, Casadevall A \& Morrison RP (Eds.). (2012). Reforming Science: Structural Reforms. Infection and Immunity, 80(3), 897-901. https://doi.org/10.1128/IAI.06184-11 PMid:22184420 PMCid:PMC3294664

6. Casadevall A \& Fang F C (2012). Reforming Science: Methodological and Cultural Reforms. Infection and Immunity, 80(3), 891-896. https://doi.org/10.1128/IAI.06183-11 PMid:22184414 PMCid:PMC3294645

7. Casadevall, A., Ellis, L. M., Davies, E. W., McFall-Ngai, M., \& Fang, F. C. (2016). A Framework for Improving the Quality of Research in the Biological Sciences. mBio, 7(4), e01256-16. https://doi.org/10.1128/mBio.01256-16 PMid:27578756 PMCid:PMC4999552 